\title{
Intravenous omeprazole after endoscopic treatment of bleeding peptic ulcers
}

Lau JYW, Sung JY, Lee KKC, et al. Effect of intravenous omeprazole on recurrent bleeding after endoscopic treatment of bleeding peptic ulcers. $N$ Engl $\mathcal{f}$ Med 2000;343:310-16.

\section{Question}

Does omeprazole reduce the risk of recurrent bleeding after successful endoscopic treatment in patients with bleeding peptic ulcer?

\section{Design}

Randomised double blind trial of 72 hours of intravenous omeprazole.

\section{Setting}

A large university hospital in Hong Kong.

\section{Patients}

A total of 240 patients with acute upper gastrointestinal bleeding endoscoped within 24 hours of admission and found to have a bleeding peptic ulcer in which bleeding was successfully controlled by endoscopic treatment.

\section{Intervention}

Bolus injection of $80 \mathrm{mg}$ intravenous omeprazole or identical placebo followed by infusion of omeprazole at 8 $\mathrm{mg} /$ hour or placebo for 72 hours. All patients were subsequently treated with oral omeprazole $20 \mathrm{mg}$ daily for eight weeks, including one week of omeprazole, clarithromycin, and amoxicillin for patients who were CLO test positive.

\section{Outcome measures}

The primary outcome measure was recurrent bleeding within 30 days. Secondary measures included blood transfusion requirement, need for surgery, duration of hospital stay, and overall mortality within 30 days.

\section{Results}

Of 739 with peptic ulcer bleeding, 267 required endoscopic treatment which was unsuccessful in five; a further 19 were excluded because of life threatening concomitant illness, and three refused consent. Rebleeding occurred in eight $(7 \%)$ of 120 randomised to intravenous omeprazole compared with $27(23 \%)$ of 120 randomised to placebo infusion (relative risk of rebleeding with placebo 3.4 (95\% confidence interval 1.6-7.1); $\mathrm{p}<0.001)$. Benefit was greatest within three days of admission when most rebleeding occurred. Patients receiving intravenous omeprazole had fewer units of blood transfused $(\mathrm{p}=0.04)$, a shorter duration of hospital stay $(p=0.02)$, and fewer operations $(p=0.14)$. After 30 days, five $(4.2 \%)$ of those given intravenous omeprazole had died compared with $12(10 \%)$ in the placebo group $(p=0.13)$; none of the deaths in the omeprazole group were attributable to recurrent bleeding in contrast with six in the placebo group.

\section{Conclusion}

After endoscopic treatment of bleeding peptic ulcers, high dose infusion of omeprazole substantially reduces the risk of recurrent bleeding.

\section{Comment}

Active ulcer bleeding can usually be stopped by therapeutic endoscopy but $15-20 \%$ of patients rebleed, usually within the first 24 hours. The rebleeding rate is similar for all endoscopic haemostatic modalities ${ }^{1}$ and combinations of endoscopic treatments are little better than single modalities. ${ }^{2}$ Patients who rebleed have a high risk of dying. Rebleeding occurs as the blood clot which is formed over the arterial defect within the ulcer base is either dislodged or dissolves. It is clear that blood clot stability is dependent on intragastric $\mathrm{pH}$ and below 5, clot lysis occurs due to the combined effects of trypsin and acid. ${ }^{3} \mathrm{~A} \mathrm{pH}$ greater than 6 is necessary for optimum platelet aggregation. Thus powerful acid suppressing drugs by stabilising the arterial plug have the potential to reduce rebleeding rates and thereby improve prognosis.

In 1992 Daneshmend and colleagues ${ }^{4}$ reported an extremely large randomised trial in which patients presenting acutely with gastrointestinal bleeding were administered intravenous boluses of omeprazole or placebo. The major end points of rebleeding and mortality were similar in both groups. This influential study persuaded the gastrointestinal community that omeprazole should not be used indiscriminately in all patients presenting with upper gastrointestinal bleeding. This conclusion is undoubtedly correct but it may not follow that acid suppressing drugs have no role in subgroups of patients. Eighty per cent of patients who present with acute gastrointestinal bleeding have an excellent prognosis without any type of intervention while at the other end of the spectrum a minority of patients will inevitably do badly because of massive bleeding or are unlikely to respond to any non-surgical therapy because they are dying from systemic disease. Thus acid suppressing drugs cannot be expected to have an impact in the majority of cases but the question arose as to whether in a subset of patients they may have a role. Close reading of the Daneshmend study showed that ulcer bleeding patients receiving omeprazole had a lower incidence of active bleeding than the placebo group at endoscopy, and although this did not translate into any differences in surgical operation rate or mortality, this trend is of interest. A criticism of this trial is that the drug regimen was insufficient to consistently increase gastric $\mathrm{pH}$ to at least 6 .

Enthusiasm for the use of proton pump inhibitors was rekindled by a study from Khuroo and colleagues. ${ }^{5}$ In this trial bleeding ulcer patients were randomised to high dose oral omeprazole or matching placebo. Rebleeding rates $(10.9 v 36.4 \%)$ and blood transfusion requirements were significantly reduced and mortality tended to be less in the omeprazole treated group. Cynics might criticise this trial 
on the basis that endoscopic therapy was not administered to any patient and the dosage regimen may not have been adequate to appropriately increase intragastric $\mathrm{pH}$. The need arose for much more focused studies in which the efficacy of these drugs was assessed following the achievement of successful endoscopic haemostasis. Two back to back trials published in the Scandinavian fournal of Gastroenterology $y^{67}$ concluded that in patients who received endoscopic haemostatic therapy for major ulcer bleeding, additional intravenous omeprazole therapy improved outcome. Unfortunately, rather ill defined and complex outcome measurements and a very low mortality in one of the studies implying relatively mild bleeding severity have somewhat decreased the impact of these studies.

A study from Lin and colleagues ${ }^{8}$ showing improved outcome in patients receiving intravenous omeprazole rather than intravenous cimetidine following endoscopic haemostasis can also be discounted because of the small number of randomised patients. The same criticism applies to the paper of Villanueva and colleagues ${ }^{9}$ in which only 86 patients were randomised to intravenous ranitidine or omeprazole following endoscopic injection.

The paper by Lau et al is therefore particularly important. The great strengths of the study are that it comes from a single centre, patients were well characterised, groups were well matched, and endoscopic therapy was administered by experts in a standard manner. Has this trial sufficient power to convince us? The authors initially calculated a need to randomise 141 patients in each group to detect an absolute reduction of $10 \%$ in rebleeding rates at an alpha level of 0.05 and a beta level of 0.8 . The trial was terminated after a third planned interim analysis because a statistically significant difference in rebleeding rates at 30 days was then apparent. This well validated statistical approach cannot be criticised but the shame is that we are again basing our practice on trials in which surrogate end points such as rebleeding, volume of transfused blood, need for a surgical operation, and duration of hospital stay are measured while the critical and important end point is mortality. Although large studies are necessary to define an effect on mortality, and appropriate trials are difficult to complete, it is a great weakness that the gastroenterology community, unlike our colleagues in cardiology and neurosciences, have not been able to effectively construct studies which are large enough to show an impact on death rates.

So where does the current study leave us? In my view the evidence has now swung to strongly support the use of high dose intravenous omeprazole therapy following successful primary haemostatic endoscopic therapy in patients presenting with major peptic ulcer bleeding. All studies show a trend for less rebleeding in treated patients, the Lau trial is the best yet and a better study will not be done. We have to decide whether or not to advocate the use of intravenous proton pump therapy on the current evidence. Although we cannot with confidence say that this approach saves lives, beneficial effects on surrogate markers such as rebleeding, transfusion requirements, need for a surgical operation, or endoscopic intervention are convincing. It seems unlikely that there are significant hazards associated with the drugs and the costs of the intravenous drug preparations are relatively modest in relation to the overall costs of managing these patients.

\section{K R PALMER}

Gastrointestinal Unit,

Lothian University Hospitals Trust,

Crewe Road, Edinburgh EH4 2XU, UK

1 Cook DJ, Gayatt GH, Salena BJ, et al. Endoscopic therapy for non-variceal hemorrhage: a meta-analysis. Gastroenterology 1992;102:139-48.

2 Chung SCS, Lau JY, Sung JJ, et al. Randomised comparison between adrenaline injection alone and adrenaline injection plus heat probe treatment for actively bleeding peptic ulcers. BMF 1997;314:1307-11.

3 Green FW, Kaplan MM, Curtis LE, et al. Effect of acid and pepsin on blood coagulation and platelet aggregation: a possible contributor to prolonged
gastroduodenal mucosal hemorrhage. Gastroenterology 1978;74:38-43.

4 Daneshmend TK, Hawkey CJ, Langman MJS, et al. Omeprazole verses placebo for acute upper gastrointestinal bleeding: randomised double blind
cond cebo for acute upper gastrointestinal
controlled trial. BMF 1992;304:143-7.

5 Khuroo MS, Yattoo GN, Javid G, et al. A comparison of omeprazole and placebo for bleeding peptic ulcer. N Engl f Med 1997;336:1054-8.

6 Hasselgren G, Lind T, Lundell L, et al. Continuous intravenous infusion of omeprazole in elderly patients with peptic ulcer bleeding: results of a placebo controlled multicenter study. Scand $\mathcal{F}$ Gastroenterol 1997;32:32833.

7 Schaffalitzky de Muckadell OB, Havelund T, Harling H, et al. Effect of omeprazole on the outcome of endoscopically treated bleeding peptic ulcers: randomized double blind placebo controlled multicenter study. Scand $\mathcal{F}$ Gastroenterol 1997;32:320-7.

8 Lin HJ, Lo WC, Lee FY, et al. A prospective randomised comparative trial showing that omeprazole prevents rebleeding in patients with bleeding peptic ulcer after successful endoscopic therapy. Arch Intern Med 1998;158: 54-8.

9 Villanueva C, Balanzo J, Torras X, et al. Omeprazole versus ranitidine as adjunct therapy to endoscopic injection in actively bleeding ulcers: a prospective randomized study. Endoscopy 1995;27:308-12.

\section{9th United European Gastroenterology Week}

The UEGW abstract book (Gut 2001;49(suppl III)) has again been produced as a CD-ROM and can be found attached to the inside back cover of this issue. 